DOI: $10.2478 /$ achi-2020-00016

\title{
IN VITRO ANTIMICROBIAL ACTIVITY OF COBALT FERRITE NANOPARTICLES SYNTHESIZED BY Co-PRECIPITATION METHOD
}

\section{Devi A. Gole ${ }^{a}$, Suresh B. Kapatkar ${ }^{a *}$, Shridhar N. Mathad ${ }^{\mathrm{b}}$, Rakesh R. Chavan ${ }^{\mathrm{c}}$}

\author{
${ }^{a}$ Department of Physics, K.L.E. Technological University, Hubli, India. \\ ${ }^{b}$ Department of Engineering Physics, K.L.E. Institute of Technology, \\ 580027, Hubballi, India. \\ ${ }^{c}$ Dr. R. B. Patil Mahesh P.U College, Hubli, India.
}

\begin{abstract}
This report presents the synthesis of cobalt ferrite with $\mathrm{pH} 7,8,9$ by coprecipitation method and its subsequent characterization by using X-ray diffraction (XRD). The synthesized cobalt ferrites were evaluated for their antibacterial and antifungal activity by agar-well diffusion method. The cobalt ferrite of $\mathrm{pH} 7$ exhibits antibacterial effect with MIC- $25 \mu \mathrm{g} \cdot \mathrm{ml}^{-1}$ against gram positive S. aureus bacterial strain compared to standard ciprofloxacin drug (MIC-6.25 $\mu \mathrm{g} \cdot \mathrm{ml}^{-1}$ ). The cobalt ferrite of $\mathrm{pH} 8$ exhibits antifungal effect with MIC-25 $\mu \mathrm{g} \cdot \mathrm{ml}^{-1}$ against Candida albicans and Rhizopus oryzae fungal strain compared to standard fluconazole drug (MIC-12.5 $\mu \mathrm{g} \cdot \mathrm{ml}^{-1}$ ).
\end{abstract}

Keywords: Cobalt ferrite, X-ray diffraction, agar-well diffusion, antibacterial and antifungal.

\footnotetext{
*Suresh B. Kapatkar, e-mail: sbkbvb@gmail.com / physicssiddu@gmail.com
} 


\section{Introduction}

Magnetic nanoparticles have been broadly studied and exploited for various basic and advanced technological applications, such as catalysts, electronic and magneto-optic devices, sensors and data storage materials. ${ }^{1,2}$ Spinel ferrites $\mathrm{M}\left(\mathrm{Fe}_{2} \mathrm{O}_{4}\right)$, where $\mathrm{M}$ represent metal (Co, $\mathrm{Zn}, \mathrm{Ni}, \mathrm{Mn}$, etc). ${ }^{3}$ Cobalt ferrites are very efficient magnetic materials owing to their high coercivity, mechanical hardness, moderate saturation magnetization $(80 \mathrm{emu} / \mathrm{g})$ and high chemical stability, it is regarded as a potential candidate in the field of recording media. ${ }^{4,5}$ In the spinel structure of Cobalt ferrites, $\mathrm{Co}^{2+}$ ions occupy octahedral B-sites while $\mathrm{Fe}^{2+}$ ions are evenly allotted among tetrahedral A-sites and octahedral B-sites. ${ }^{6,7}$ Cobalt ferrite is a rigid ferrimagnetic material since it has high squareness ratio, high saturation magnetization and greater magneto-crystalline anisotropy with a positive anisotropy constant. ${ }^{8}$

Recent advances in nanotechnology, chiefly the development of nanoparticles for drug delivery, have produced noteworthy impact in healthcare and medicine. ${ }^{9,10}$ Nanomaterials are used for the development of diagnostic tools like bio-imaging, bio-sensing, and many others. ${ }^{11}$ In general nano range particles exhibit a higher surface area-to volume ratio. The specific surface area is significant for catalytic activity such as antimicrobial activity of nanoparticles. ${ }^{12,13}$ With increase in the specific surface area of nanoparticles, their biological efficiency can also increase on the account of a rise in surface energy.

The problems of multidrug-resistant (MDR) microorganisms have arrived at an alarming level in many countries around the world. The variety of clinically significant species of bacteria has developed resistance to a number of anti-microbial agents and this is becoming increasingly important 
global problem. ${ }^{14}$ Due to the alkalinity and active oxygen species of $\mathrm{CoO}$, they provide strong antibacterial activity. ${ }^{15}$ The antimicrobial nanoparticle formulations are increasingly investigated and many are under various stages of pre-clinical and clinical tests. ${ }^{16,17}$ Candida albicans a dimorphic fungi cause $90 \%$ candidacy in mammals and humans. ${ }^{18,19}$ It is also causing nasocomial infection and approximate vaginal infection. ${ }^{20}$ Escherichia coli is a major organism of water borne infection and nosocomial with higher mortality and morbidity rates is the other organism used in this study. ${ }^{21}$ Over view of literature survey, the importance of nanoparticle cobalt ferrites in the biological systems may result in antimicrobial activity.

In this present work, we report the synthesis of nano cobalt ferrite with $\mathrm{pH} 7,8,9$ by environmental friendly, low cost co-precipitation method, the structural properties of cobalt ferrite $\left(\mathrm{CoFe}_{2} \mathrm{O}_{4}\right)$ by XRD and studied the influence of $\mathrm{pH} 7, \mathrm{pH} 8$ and $\mathrm{pH} 9$ on in vitro antibacterial and antifungal activities.

\section{Experimental}

Synthesis of cobalt ferrite

The nano cobalt ferrite $\left(\mathrm{CoFe}_{2} \mathrm{O}_{4}\right)$ is synthesized by environmental friendly and low cost chemical co-precipitation method by choosing the analytical grade (molychem) $\mathrm{CoCl}_{2} \cdot 6 \mathrm{H}_{2} \mathrm{O}$ and $\mathrm{FeCl}_{3}$. These precursors are weighed and mixed in desired stiochiometric ratio in distilled water. The reactants are stirred for nearly one hour to get clean solution. In order to maintain $\mathrm{pH}$ of 7, 8 and 9 drop wise ammonia solution is added and again stirred for one hour. The reddish solution so obtained contains precipitate which is filtered to get the cobalt ferrite using AR grade filter paper. The paste from precipitate is dried at room temperature and annealed around $800{ }^{\circ} \mathrm{C}$ in muffle furnace for $5 \mathrm{hr}$ which will yields the nano cobalt ferrite. ${ }^{24,25}$ The 
process of synthesis of nano cobalt ferrite by co-precipitation method is schematically as shown in Figure 1.

$$
\mathrm{CoCl}_{2} .6 \mathrm{H}_{2} \mathrm{O}+2 \mathrm{FeCl}_{3} .9 \mathrm{H}_{2} \mathrm{O}+8 \mathrm{NH}_{4} \mathrm{OH} \rightarrow \mathrm{CoFe}_{2} \mathrm{O}_{4}+8 \mathrm{NH}_{4} \mathrm{Cl}+28 \mathrm{H}_{2} \mathrm{O}
$$

The X-ray diffraction patterns of the samples have been obtained on Bruker AXS D8 Advance Diffractometer (XRD) with $\mathrm{Cu}-\mathrm{K} \alpha$ radiation, wavelength, $\lambda=1.5406 \AA$.

\section{Results and discussion}

$X R D$

The sample structure is interpreted using the XRD analysis. The XRD image of cobalt ferrite $\left(\mathrm{CoFe}_{2} \mathrm{O}_{4}\right)$ at $\mathrm{pH}=7,8$ and 9 is presented in Figure 1. The lattice parameter of series is calculated using equation (2) and tabulated in Table 1 - 4.

$$
d=\frac{a}{\left(h^{2}+k^{2}+l^{2}\right)^{1 / 2}}
$$

where d - interplanar spacing, a - lattice parameter and (h k l) - Miller indices. Average crystalline size can be calculated by Debye-Scherrer's formula. $^{22}$

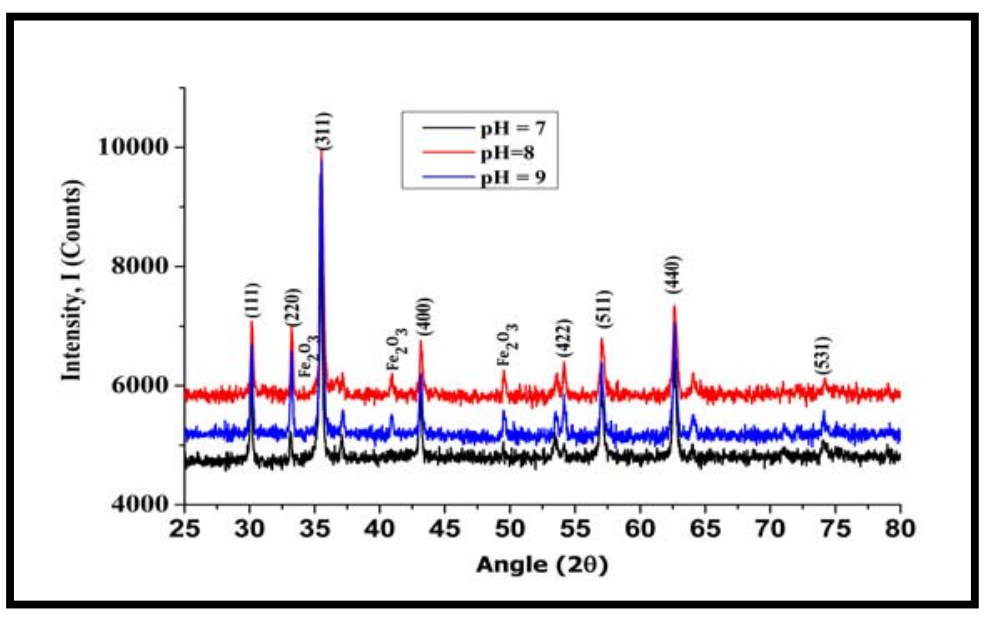

Figure 1. XRD comparative intensity plot of cobalt ferrite $\left(\mathrm{CoFe}_{2} \mathrm{O}_{4}\right)$. 


$$
D=\frac{K . . \lambda}{\beta \cdot \cos \theta}
$$

where, D- crystalline size, K- crystalline shape factor which is taken to be 0.9 in this case considering the particles to be spherical in common, $\lambda$ - wavelength of $\mathrm{X}$-ray used $\left(1.5406 \mathrm{~A}^{0}\right), \beta_{\mathrm{D}}$-pure diffraction broadening.

Table 1. Calculated values of Lattice parameter (a) and crystallite size (D) for $\mathrm{CoFe}_{2} \mathrm{O}_{4}$ samples $(\mathbf{p H}=7)$.

\begin{tabular}{|c|c|c|c|c|c|c|}
\hline Angle $2 \theta$ & 30.052 & 35.328 & 43.034 & 53.379 & 57.052 & 62.534 \\
\hline Lattice parameter (a) (Å) & 8.4089 & 8.4242 & 8.4080 & 8.4066 & 8.3866 & 8.4004 \\
\hline Crystallite size (D) (Å) & 442 & 359 & 348 & 266 & 280 & 272 \\
\hline
\end{tabular}

Table 2. Calculated values of Lattice parameter (a) and crystallite size (D) for $\mathrm{CoFe}_{2} \mathrm{O}_{4}$ samples $(\mathbf{p H}=\mathbf{8})$.

\begin{tabular}{|c|c|c|c|c|c|c|}
\hline Angle $2 \theta$ & 30.207 & 35.483 & 43.19 & 54.103 & 57.052 & 62.69 \\
\hline Lattice parameter (a) (§̊) & 8.3637 & 8.3846 & 8.3728 & 8.2993 & 8.3824 & 8.3781 \\
\hline Crystallite size (D) (§) & 413 & 326 & 351 & 307 & 275 & 233 \\
\hline
\end{tabular}

Table 3. Calculated values of Lattice parameter (a) and crystallite size (D) for $\mathrm{CoFe}_{2} \mathrm{O}_{4}$ samples $(\mathbf{p H}=\mathbf{9})$.

\begin{tabular}{|c|c|c|c|c|c|c|}
\hline Angle $2 \theta$ & 30.052 & 35.483 & 43.034 & 54.103 & 57.052 & 62.69 \\
\hline Lattice parameter (a) ( $($ ) & 8.4056 & 8.3846 & 8.4025 & 8.2993 & 8.3824 & 8.3781 \\
\hline Crystallite size (D) (Å) & 426 & 319 & 337 & 435 & 309 & 279 \\
\hline
\end{tabular}

Table 4. Calculated average values of Lattice parameter (a) and crystallite size (D) for $\mathrm{CoFe}_{2} \mathrm{O}_{4}$ samples $(\mathbf{p H}=\mathbf{7 ,}, \mathbf{8}, \mathbf{9})$.

\begin{tabular}{c|ccc}
\hline $\mathbf{p H}$ & 7 & 8 & 9 \\
Lattice parameter (a) $(\mathbf{\AA})$ & 8.4057 & 8.3561 & 8.3754 \\
Crystallite size (D) $(\mathbf{\AA})$ & 328 & 318 & 351 \\
\hline
\end{tabular}


From X-ray figure we can observe a maximum (311 peak) at $2 \theta$, 35.328 degrees for $\mathrm{pH} 7,35.483$ degrees for $\mathrm{pH} 8$ and 35.483 degrees for $\mathrm{pH} 9$ that can be attributed to spinel structure. The Miller indices (111), (2 2 0), (3 11 1), (4 00 0 $),\left(\begin{array}{lll}4 & 2 & 2\end{array}\right),(5 \quad 11),(440)$ and (531) confirms the cubic phase $^{22}$. The peaks in the XRD graphs at $33.3^{\circ}, 40.9^{\circ}$ and $49.5^{\circ}$ corresponds to Hematite $\alpha-\mathrm{Fe}_{2} \mathrm{O}_{3}$ with JCPDS number 33-0664 $\left(\alpha-\mathrm{Fe}_{2} \mathrm{O}_{3}\right)^{23}$. The Crystallite size (D) of synthesized cobalt ferrites is lowest for $\mathrm{pH} 8$ with 318 $\AA$ and highest for $\mathrm{pH} 9$ with $351.1 \AA$. The lattice parameter values are highest for cobalt ferrites with $\mathrm{pH} 7$ when compared with $\mathrm{pH} 8$ and $\mathrm{pH} 9$. The X-ray diffraction confirms the structure of cobalt ferrites.

\section{Pharmacological screening}

In vitro antibacterial screening

The nano cobalt ferrites were screened for in vitro antibacterial activity by agar-well diffusion method ${ }^{24}$ against two Gram-positive (Bacillus subtilis (ATCC no. 23857) and Staphylococcus aureus (ATCC29213)) and two Gram-negative (Escherichia coli (ATCC-25922) and P. aeruginosa (ATCC No. 25619)) bacterial strains. The minimum inhibitory concentration (MIC) of the synthesized compounds (1-3) and ciprofloxacin was compared, it revealed that few of the synthesized compounds exhibited good antibacterial activity against Gram-positive $S$. aureus bacterial strain. Screening results are summarized in Table 5. The best antibacterial effect was observed for cobalt ferrites of $\mathrm{pH} 7$ and $\mathrm{pH} 8$ with MIC $25 \mu \mathrm{g} \cdot \mathrm{ml}^{-1}$ each against Gram-positive $S$. aureus bacterial strain. While cobalt ferrites of $\mathrm{pH} 9$ exhibited MIC $25 \mu \mathrm{g} \cdot \mathrm{ml}^{-1}$ against Gramnegative $P$. aeruginosa bacterial strain. The results are also represented in bar diagram of Figure 2. 
Table 5. In-vitro antibacterial screening for compounds.

\begin{tabular}{ccccc}
\hline & \multicolumn{3}{c}{$\begin{array}{c}\text { Micro-organisms used for Antibacterial Activity } \\
\text { (MIC } \boldsymbol{\mu g} / \mathbf{m L})\end{array}$} \\
\cline { 2 - 5 } $\mathbf{C o F e}_{2} \mathbf{O}_{4}$ & \multicolumn{4}{c}{ Gram negitive } \\
\cline { 2 - 5 } $\mathbf{p H}$ & 25 & 25 & 50 & 100 \\
\cline { 2 - 4 } & 100 & 25 & 100 & 50 \\
7 & 50 & 50 & 100 & 25 \\
9 & 6.25 & 6.25 & 3.125 & 6.25 \\
\hline
\end{tabular}

${ }^{\mathrm{a}}$ Ciprofloxacin was used as a positive control against bacteria species.

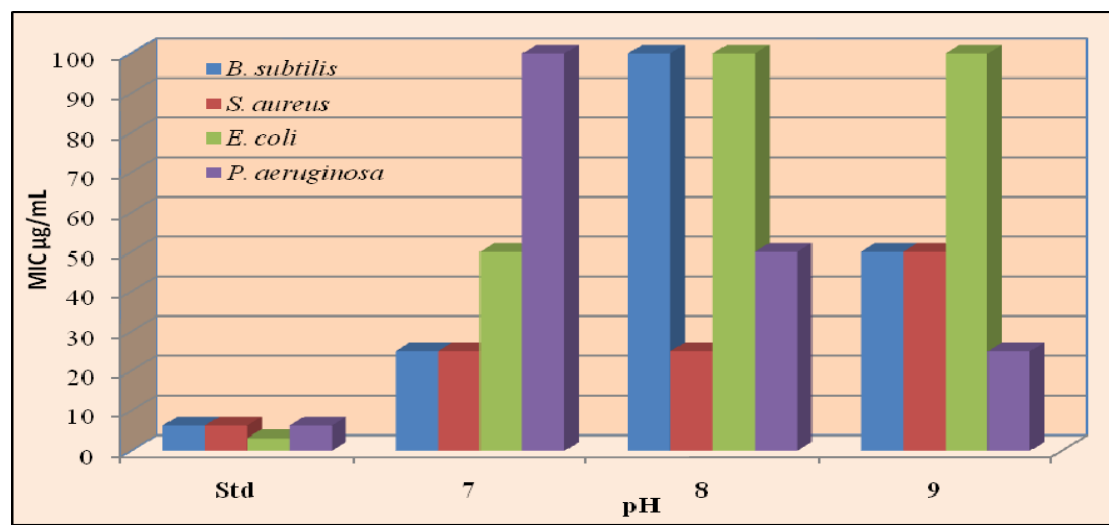

Figure 2. Graphical representation of Minimum inhibitory concentrations (MIC) $(\mu \mathrm{g} / \mathrm{mL})$ of all cobalt ferrites against Bacillus subtilis, Staphylococcus aureus, Escherichia coli and $P$. aeruginosa.

\section{In vitro antifungal screening}

The antifungal activity was evaluated against fungal strain such as Aspergillus fumigatus, Candida albicans, Penicillium chrysogenum and Rhizopus oryzae. Fluconazole was used as a standard for the comparison of antifungal activity and Minimum inhibitory concentration (MIC) values were determined. The antifungal screening data revealed that, the synthesized compounds exhibited good antifungal activity against 
Penicillium chrysogenum fungal strain. Screening results are summarized in Table 6 . The best antifungal effect was observed for cobalt ferrites of $\mathrm{pH} 8$ with MIC $25 \mu \mathrm{g} \cdot \mathrm{ml}^{-1}$ each against Candida albicans and Rhizopus oryzae fungal strain. The results are also represented in bar diagram of Figure 3. Finally, these compounds could be further optimized for future development of more potent and selective antimicrobial agents.

Table 6. In-vitro antifungal screening for compounds (1-3).

\section{Micro-organisms used for Antifungal Activity (MIC}

$\mathrm{CoFe}_{2} \mathrm{O}_{4}$ pH

7

8

9

\begin{tabular}{cccc}
\multicolumn{4}{c}{$\mathbf{g} / \mathbf{m L})^{*}$} \\
\hline $\begin{array}{c}\text { Aspergillus } \\
\text { fumigatus }\end{array}$ & $\begin{array}{c}\text { Candida } \\
\text { albicans }\end{array}$ & $\begin{array}{c}\text { Penicillium } \\
\text { chrysogenum }\end{array}$ & $\begin{array}{c}\text { Rhizopus } \\
\text { oryzae }\end{array}$ \\
\hline 50 & 100 & 25 & 100 \\
100 & 25 & 50 & 25 \\
100 & 50 & 25 & 50
\end{tabular}

Fluconazole $^{\mathrm{a}}$

25

25

12.5

12.5

${ }^{a}$ Fluconazole was used as a positive control against fungal species.

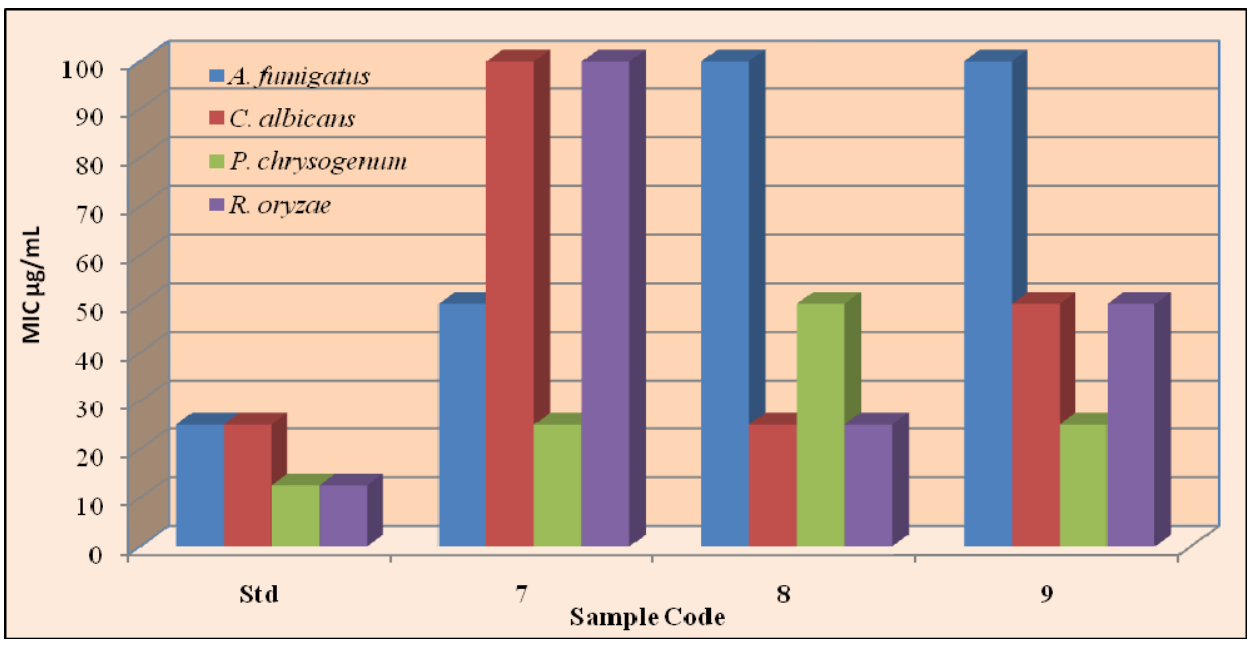

Figure 3. Graphical representation of Minimum inhibitory concentrations (MIC) $(\mu \mathrm{g} / \mathrm{mL})$ of all cobalt ferrites against Aspergillus fumigatus, Candida albicans, Penicillium chrysogenum and Rhizopus oryzae. 
Biological assay methods

\section{Antibacterial activity}

The nano cobalt ferrites $\mathrm{pH} \mathrm{7,8}$ and 9 were screened for in vitro antibacterial activity by agar-well diffusion method ${ }^{24}$ against two Grampositive (Bacillus subtilis (ATCC no. 23857) and Staphylococcus aureus (ATCC-12598)) and two Gram-negative (Escherichia coli (ATCC-25922) and Pseudomonas aeruginosa (ATCC No. 25619)) bacterial strains. In this experiment, antibiotic ciprofloxacin was used as reference standard to compare antibacterial activities. The synthesized compounds were dissolved in dimethyl sulfoxide (the stock solution $1 \mathrm{mg} \cdot \mathrm{ml}^{-1}$ ). Furthermore, the dilutions were prepared at the required quantities of 100,50 and $25 \mu \mathrm{g} \cdot \mathrm{ml}^{-1}$ concentrations. To ensure that the solvent had no effect on bacterial growth, control test was also performed containing disc loaded with only DMSO at the same dilution used in our experiment. Test compound solutions prepared in DMSO were serially diluted and loaded $(10 \mu 1)$ to sterile filter paper discs (6mm diameter), which finally contained $\left(25,50\right.$ and $\left.100 \mu \mathrm{g} \cdot \mathrm{ml}^{-1}\right)$ of the compound per disc, respectively. Impregnated discs were then dried for $1 \mathrm{~h}$ and placed on inoculated plates. The seeded plates were incubated at $37{ }^{\circ} \mathrm{C}$ for $16 \mathrm{~h}$. The radii of inhibition zones (in $\mathrm{mm}$ ) were measured and the percentage inhibition of test compounds was related to the standard drug whose zone of inhibition was taken as $100 \%$. The results of minimum inhibitory concentrations (MICs) of the synthesized compounds against bacterial species are determined.

\section{Anti-fungal activity}

The nano cobalt ferrites $\mathrm{pH} \mathrm{7,8}$ and 9 were screened for in-vitro anti-fungal activity by agar-well diffusion method ${ }^{24-27}$ against fungal strain such as Aspergillus fumigatus, Candida albicans, Penicillium chrysogenum 
and Rhizopus oryzae. In this experiment, Fluconazole was used as a standard for the comparison of antifungal activity. Minimum inhibitory concentration (MIC) values were determined using standard disc diffusion method. The tests were carried out at a concentration of $100 \mu \mathrm{g} \cdot \mathrm{mL}^{-1}$, $50 \mu \mathrm{g} \cdot \mathrm{mL}^{-1}, 25 \mu \mathrm{gm} \cdot \mathrm{L}^{-1}$ and $12.5 \mu \mathrm{gm} \cdot \mathrm{L}^{-1}$. After $48 \mathrm{hrs}$ of incubation at $37{ }^{\circ} \mathrm{C}$, the zone of inhibition was measured in millimeters. The percentage inhibition of test compounds was related to the standard whose zone of inhibition was taken as $100 \%$.

\section{Conclusion}

In summary, we have synthesized nano cobalt ferrites with $\mathrm{pH} 7,8$ and 9 by co-precipitation method. The X-ray diffraction confirms the structure of cobalt ferrites. In vitro antibacterial activity assays revealed cobalt ferrites of $\mathrm{pH} 7$ (MIC $25 \mu \mathrm{g} \cdot \mathrm{ml}^{-1}$ ) with highest antibacterial activity and this series of compounds also possesses selective antibacterial inhibitory activity toward Gram-positive bacteria S. aureus over Gramnegative bacteria. The antifungal activity showed cobalt ferrites of $\mathrm{pH} 8$ (MIC $25 \mu \mathrm{g} \cdot \mathrm{ml}^{-1}$ ) with good antifungal activity.

\section{Acknowledgments}

The authors thank B.V.B. College of Engineering and Technology, Hubli, University Sophisticated Instrumentation Centre (USIC), Karnatak University Dharwad and Indian Institute of Science (IISc), Bangalore, India for providing spectral analysis.

\section{References}

1. Wang, L.; Wen, B.; Bai, X.; Liu, C.; Yang, H. Facile and green approach to the synthesis of zeolitic imidazolate framework nanosheet-derived $2 \mathrm{D} \mathrm{Co} / \mathrm{C}$ composites for a lightweight and highly efficient microwave absorber. $J$. Colloid Interface Sci. 2019, 540, 30-38.

2. Dong, J.; Lin, Y.; Zong, H.; Yang, H.; Wang, L.; Dai, Z. Three-Dimensional Architecture Reduced Graphene Oxide- $\mathrm{LiFePO}_{4}$ Composite: Preparation and Excellent Microwave Absorption Performance. Inorg. Chem. 2019, 58, 2031-2041. 
3. Hossain, M. S.; Alamy, M. B.; Shahjahan, M. M.; Begum, H. A.; Hossain, M. M.; Islam, S.; Khatun, N.; Hossain, M.; Alam M. S.; Mamun, M. A. Synthesis, structural investigation, dielectric and magnetic properties of $\mathrm{Zn}_{2}$ p-doped cobalt ferrite by the sol-gel technique. J. Adv. Dielectrics. 2018, 8(4), 1850030.

4. Lee, J. G.; Park J. Y.; Kim, C. S. Growth of ultra-fine cobalt ferrite particles by a sol-gel method and their magnetic properties. J. Mater. Sci. 1998, 33, 3965 3968.

5. Okauno, S. N.; Hanshimoto, S.; Inomata, K. Preferred crystal orientation of cobalt ferrite thin films induced by ion bombardment during deposition, $J$. Appl. Phys. 1992, 71(12), 5926-5929.

6. Rahman, M. A.; Hossain, M. M.; Islam M. S.; Sarker, M. A. R. First-principle investigation of doping effects on electronic, elastic, thermal and optical properties of $\mathrm{CoFe}_{2} \mathrm{O}_{4}$. Appl. Res. J. 2015, 1(3), 127-136.

7. Hossain, M. T.; Islam, S.; Mondal M. H.; Khan, A. H. Studies on anomalous behavior at curie point, Tc of some classes of mixed ferrites. Bangladesh $J$. Sci. Ind. Res. 2006, 41(3), 171-180

8. Jadoun, P.; Sharma, J.; Kumar, S.; Dolia, S. N.; Bhatnagar, D.; Saxen, V. K. Structural and magnetic behavior of nanocrystalline $\mathrm{Cr}$ doped $\mathrm{Co}-\mathrm{Mg}$ ferrite. Ceram. Int. 2018, 44, 6747-6753.

9. Farokhzad, O. C.; Langer, R. Impact of nanotechnology on drug delivery, ACS Nano 2009, 3, 16-20.

10. Shi, J.; Votruba, A. R.; Farokhzad, O. C.; Langer, R. Nanotechnology in drug delivery and tissue engineering: From discovery to applications. Nano Lett. 2010, 10, 3223-3230.

11. Cruz Paula, A. Da.; Marques, O.; Sampaio, R.; Rosa, A.; Garcia, J.; Rema, A.; Faria, F.; Silva, P.; Vizcaino, R.; Lopes, C.; Characterization of CD44 $\mathrm{ALDH}^{+}{ }^{+} \mathrm{Ki}-67^{-}$cells in non-malignant and neoplastic lesions of the breast. Anticancer Res. 2016, 36, 4629-4638.

12. Krishnaraj, C.; Jagan, E. G.; Rajasekar, S.; Selvakumar, P.; Kalaichelvan, P. T.; Mohan, N. Synthesis of silver nanoparticles using Acalypha indica leaf extracts and its antimicrobial activity against water borne pathogens. Colloid Surf. B Biointer. 2010, 76, 50-56.

13. Saxena, A.; Tripathi, R. M.; Zafar, F.; Singh, P.; Green synthesis of silver nanoparticles using an aqueous solution of Ficus benghalensis leaf extract and characterization of their antimicrobial activity. Mater. Lett. 2012, 67, 91-94.

14. Chavan, R. R.; Hosamani, K. M.; Kulkarni, B. D.; Joshi, S. D. Molecular docking studies and facile synthesis of most potent biologically active N-tertbutyl-4-(4-substituted phenyl)-2-((substituted-2-oxo-2H-chromen-4-yl) 
methylthio)-6-oxo-1,6-dihydropyrimidine-5-carboxamide hybrids: An approach for microwave-assisted syntheses and biological evaluation. Bioorg. Chem. 2018, 78, 185-194.

15. Jin, T.; He, Y. Antibacterial activities of magnesium oxide (MgO) nanoparticles against food borne pathogens. J. Nanopart. Res. 2011, 13, $6877-$ 6885.

16. Zhang, L.; Pornpattananangkul, D.; Hu, C. M. J.; Huang, C. M. Development of nanoparticles for antimicrobial drug delivery. Curr. Med. Chem. 2010, 17, 585-594.

17. Gao, W.; Thamphiwatana, S.; Angsantikul, P.; Zhang, L. Nanoparticle approaches against bacterial infections. Wiley Interdiscip. Rev.: Nanomed. Nanobiotechnol. 2014, 6, 532-547.

18. Martins, N.; Ferreira, I. C.; Barros, L.; Silva, S.; Henriques, M. Candidiasis: predisposing factors, prevention, diagnosis and alternative treatment. Mycopathologia 2014, 177, 223-240.

19. Mukherjee, P. K.; Sendid, B.; Hoarau, G.; Colombel, J. F.; Poulain, D.; Ghannoum, M. A. Mycobiota in gastrointestinal diseases. Nat. Rev. Gastroenterol. Hepatol. 2015, 12, 77-87.

20. Tortora, J. G.; Funke R. B.; Case L. C. Microbiology An Introduction; Benjamin Cummings; San Francisco, pp. 88-95.

21. Khan, H. A.; Ahmad, A.; Mehboob, R. Nosocomial infections and their control strategies. Asian Paci. J. Tropi. Biomed. 2015, 5, 509-514.

22. Yattinahalli, S. S.; Kapatkar, S. B.; Ayachit, N. H.; Mathad, S. N. Synthesis and structural characterization of nanosized nickel ferrite. Int. J. Self Propag. High Temp. Synth. 2013, 22(3), 147-150.

23. Verma, K.C.; Goyal, Navdeep; Singh, Manpreet; Singh, Mukhwinder; Kotnalad, R. K. Hematite $\alpha-\mathrm{Fe}_{2} \mathrm{O}_{3}$ induced magnetic and electrical behavior of $\mathrm{NiFe}_{2} \mathrm{O}_{4}$ and $\mathrm{CoFe}_{2} \mathrm{O}_{4}$ ferrite nanoparticles. Results in Physics 2019, 13, 102212.

24. Rahman, A., Choudhary, M. I., Thomsen W. J. Bioassay techniques for drug development. Amsterdam, Netherlands: Harwood Academic Publishers, 2001.

25. Yattinahalli, S. S.; Kapatkar, S. B.; Mathad, S. N. Structural studies of zinc ferrite synthesized at low temperature. The International Reviewer 2014, 1(1), 5-8.

26. Yattinahalli, S. S.; Kapatkar, S. B.; Mathad, S. N. Synthesis and Structural Characterization of Nanomanganese Ferrites. J. Nano- Electron. Phys. 2015, 7(4), 04096-04099.

27. Isenberg, H. D. Clinical Microbiology Procedures Handbook, American society for microbiology/Washington, D.C., 1992. 